\title{
Kajian Pemanfaatan Silika dari Sekam Padi dalam Pengolahan Limbah Tekstil
}

\author{
Isma Masrofah $^{1}$ \\ ${ }^{1}$ Program Studi Teknik Industri Fakultas Teknik Universitas Suryakancana \\ Jl. Pasir Gede Raya Cianjur 43216 \\ isma.masrofah@unsur.ac.id
}

Dikirimkan: 11, 2017. Diterima: 12, 2017). Dipublikasikan: 12, 2017.

\begin{abstract}
Textile industry is one of the waste contamination industries that can pollute the environment, so that the rapid development of textile industry must be followed by the improvement of its sewage treatment system. Along with the global issue of Green Manufacturing, the textile industry waste treatment can promote environmentally friendly waste treatment process and derived from renewable substances. Therefore, it is necessary to study the utilization of rice husk silica in the processing of textile waste. The purpose of this literature review process is to provide information on textile waste, silica from rice husk and its properties, and textile waste treatment mechanism using silica from rice husks. The results of the study provide information that textile wastes come from all processes in the textile industry, from pretreatment to finishing. Rice husk ash silica is a material utilized adsorption of textile waste or mixture of PolyVinylChloride (PVC) membrane material to filter textile waste. The characteristics of rice husk silica are influenced by the extraction method. The initial washing process using acid and then combustion at $600^{\circ} \mathrm{C}-750{ }^{\circ} \mathrm{C}$ produces a relatively high purity of silica with a maintained silica amorphous level.
\end{abstract}

Keywords: Rice Husk Silica, Textile Waste, Textile Waste Processing, Silica Characteristic

\begin{abstract}
Abstrak - Industri tekstil merupakan salah satu industri penyumbang limbah yang dapat mencemari lingkungan, sehingga pesatnya perkembangan industri tekstil harus diikuti pula dengan peningkatan sistem pengolahan limbahnya. Seiring dengan isu global tentang Green Manufacturing, maka pengolahan limbah industri tekstil dapat mengedepankan proses pengolahan limbah yang ramah lingkungan dan berasal dari zat yang terbarukan. Oleh karena itu, perlu kajian mengenai pemanfaatan silika sekam padi dalam pengolahan limbah tekstil. Tujuan proses kajian literatur ini yaitu untuk memberikan infomasi mengenai limbah tekstil, silika dari sekam padi dan sifatnya, serta mekanime pengolahan limbah tekstil menggunakan silika dari sekam padi. Hasil kajian memberikan informasi bahwa limbah-limbah tekstil bersumber dari semua proses dalam industri teksil, mulai dari pretreatment sampai dengan finishing. Silika abu sekam padi merupakan material yang dimanfaatkan adsorpsi limbah tekstil atau campuran bahan membran PolyVinilChlorida (PVC) untuk menyaring limbah tekstil. Karakteristik silika sekam padi dipengaruhi cara ekstraksi. Proses pecucian awal menggunakan asam kemudian pembakaran pada suhu $600{ }^{\circ} \mathrm{C}-750{ }^{\circ} \mathrm{C}$ mengasilkan kemurnian silika yang relatif tinggi dengan tingkat keamorfan silika yang masih terjaga.
\end{abstract}

Kata kunci: Kata Kunci: Silika Sekam Padi, Limbah Tekstil, Pengolahan Limbah Tekstil, Karakteristik Silika

\begin{abstract}
I. Pendahuluan
Pesatnya perkembangan industri di Indonesia, termasuk industri tekstil mengakibatkatkan adanya peningkatan limbah yang berdampak terhadap pencemaran lingkungan, baik itu lingkungan air, darat maupun udara Hal ini bertolak belakang dengan adanya isu Go Green yang sedang digalakan di setiap Negara.

Oleh karena itu, adanya perkembangan industri ini harus diikuti pula dengan alternatif
\end{abstract}

penanganan dampak yang akan ditimbulkan. Dampak yang timbulkan misalnya pada penurunan kualitas air untuk konsumsi masyarakat dan pertanian. Air menjadi tidak layak dikonsumsi karena berubah warna, tingkat kesadahan meningkat, terjadi peningkatan $\mathrm{pH}$, dan lain-lain.

Kondisi seperti itu, bertentangan dengan salah satu indikator Go Green yaitu dengan melaksanakan Green Manufacturing, yang menjadi komitmen beberapa negara di dunia, termasuk para pelaku industri untuk 
meningkatkan perhatian dan kesadaranya dalam aspek lingkungan, dengan menerapkan proses/sistem yang meminimalkan dampak negatif terhadap lingkungan[1]. Begitupun halnya proses pengolahan limbah padat maupun limbah cair yang dihasilkan oleh industri tekstil dapat dilakukan dengan pemanfaatan absorben yang terbarukan sehingga diharapkan akan lebih ramah lingkungan.

Guna menunjang hal tersebut, pemanfaatan silika dari sekam padi sebagai absorben menjadi cara alternatif yang lebih ramah lingkungan dan ekonomis karena berasal dari alam serta dapat mengurangi limbah hasil pertanian. Menurut Danarto dalam Nurhasni, sekam padi memiliki nilai gizinya rendah, tahan terhadap pelapukan, memiliki kandungan abu yang tinggi, bersifat abrasif, menyerupai kandungan kayu, serta memiliki kandungan karbon yang cukup tinggi [2]. Komposisi tertinggi dalam abu sekam padi adalah silica $(\mathrm{SiO} 2)$ yaitu sekitar $86.9-96.3 \%$ [3], $87-97 \%$ [4].

Selain merupakan bahan terbarukan, proses ekstraksi silika relatif mudah dalam mendapatkan silika dari sekam padi yaitu dengan pembakaran pada suhu $\square 500$ oC[3], silika amorf dengan kemurnian $99 \%$ dihasilkan dari sekam padi melalui proses pencucian dengan asam klorida atau asam sulfat yang diikuti dengan proses pembakaran pada suhu $600 \mathrm{oC}$ selama 2 jam [5]

Makalah ini bertujuan untuk memberikan informasi mengenai limbah yang dihasilkan oleh industri teksil, mengetahui silika dari sekam padi dan sifatnya, serta mekanisme pengolahan limbah tekstil menggunakan silika dari sekam padi.

\section{Metodologi Penelitian}

Metode penelitian yang digunakan adalah deskriptif kualitatif dengan teknik kajian literatur. Kajian yang digunakan dalam mendapatkan informasi untuk mengkaji pemanfaatan silika sekam padi dalam pengolahan limbah tekstil, yaitu dengan melakukan studi literatur dari berbagai artikel, makalah dan jurnal yang terkait dari media elektronik. Proses pencarian literatur tersebut melalui data base berbagai situs pencarian literatur seperti, Google Scholar, Science Direct, Elsevier, Directory of Open Access Journals (DOAJ) dan International of Electrical and Electronics Engineers (IEEE).

Melalui situs-situs tersebut diperoleh ratusan artikel, makalah dan jurnal. Beberapa dari literatur yang dihasilkan tersebut dipilih yang sesuai dengan proses kajian pemanfaatan silika sekam padi dalam pengolahan limbah tekstil serta dapat menunjang kelancaran proses kajian.

Pembahasan dari kajian ini yaitu dimulai dengan mengkaji limbah tekstil, literature yang digunakan dalam kajian ini yaitu jurnal, seksi buku yang berisisi penelitian-penelitian yang terkait dengan limbah tekstil, dengan juduljudul: Application of Electro-Oxidation Method for Treatment of Dye Textile Wastewater Using Stainless Steel Electrode: Study of Electrolyte Concentration Effect to Color Remova, Characterization and Treatment of Textile Wastewater, Textile Water Treatment.

Bagian kedua dari pembahasan yaitu mengenai silika abu sekam padi. Pada Subbab ini dijelaskan bagaimana mengestraski silika dari sekam padi serta karakteristik silika sekam padi. Bagian ketiga dari pembahasan yaitu menjelaskan tentang mekanisme pengolahan limbah tekstil dengan silika sekam padi. Pada subbab ini dijelaskan mengenai teknik yang dapat digunakan dalam pemanfaatan silika sekam padi sebagai zat untuk mengolah limbah tekstil.

\section{PEMBAHASAN}

\subsection{Limbah Tekstil}

Proses industri tekstil dimulai proses pretreatment sampai dengan finishing. Keseluruan proses ini akan memberikan limbah tekstil, baik itu limbah organik maupun limbah anorganik. Adapun contoh jenis polutan utama pada limbah cair tekstil dan asal proses limbah itu dihasilkan dapat dilihat pada Tabel I.

Proses basah yang biasa dilakukan di industri tekstil meliputi singeing, sizing, desizing, scouring, bleaching, mercerization, dyeing, printing, finishing. Setiap proses tersebut dalam industri tekstil dibutuhkan air, sehingga berdampak pada timbulnya limbah cair tekstil, apa bila pada industri tekstil tersebut tidak dilakukan proses pengolahan limbah.

Tabel I memperlihatkan bahwa polutan dri limbah tektil berasal dari semua proses yang ada di industri tekstil mulai dari pretreatment sampai dengan fininshing.

Parameter yang penting dalam limbah tekstil diantaranya : warna, $\mathrm{pH}$, konduktivitas, Chemical Oxygen Demand (COD), Biochemichal Oxygen Demand (BOD), kesadahan, minyak, lemak, klorida, fenol, Total Dissolved Solids (TDSs), alkalinitas total, florida, sulfat, silika, sodium, logam-logam berat $(\mathrm{Cu}, \mathrm{Pb}, \mathrm{Mn}$, dan $\mathrm{Cd})[6]$. 


\section{JMTS|}

komposisi dan karakteristik limbah industri tekstil dapat di lihat di Tabel II.

Proses pengolahan limbah tekstil bisa dilakukan dengan cara konvensional (koagulasi, adorpsi, oksidasi, dan dengan penguraian warna secara biologi) dan dengan teknologi terbaru seperti, elektrik, sonik, magnetik, optik dan metode-metode termal. Limbah tekstil yang kompleks memerlukan kombinasi pengolahan menggunkan proses bilogi,fisika dan kimia, pengolahan system membrane lebih sesuai dalam menangani jenis seperti limbah yang kompleks [7].

TABEL I

Jenis Polutan Utama Dalam Limbah Cair Tekstil DAN PRoses Asalnya

\begin{tabular}{|c|c|c|}
\hline Polutan & $\begin{array}{l}\text { Jenis Bahan } \\
\text { Kimia Utama }\end{array}$ & $\begin{array}{l}\text { Proses Utama } \\
\text { Asal }\end{array}$ \\
\hline Bahan Organik & $\begin{array}{l}\text { Pati, Enzim, } \\
\text { Lemak, Minyak, } \\
\text { Lilin, Surfaktan, } \\
\text { Asam Asetat }\end{array}$ & $\begin{array}{l}\text { Desizing, } \\
\text { bleaching, } \\
\text { dyeing }\end{array}$ \\
\hline Pewarna & $\begin{array}{l}\text { Zat warna, } \\
\text { pembersihan } \\
\text { kotoran wol }\end{array}$ & Dyeing \\
\hline $\begin{array}{l}\text { Nutrisi (N dan } \\
\text { P) }\end{array}$ & $\begin{array}{l}\text { Garam-garam } \\
\text { ammonium, } \\
\text { penyangga } \\
\text { berbasis urea } \\
\text { fosfat }\end{array}$ & Dyeing \\
\hline $\begin{array}{l}\text { Efek PH dan } \\
\text { Garam }\end{array}$ & $\begin{array}{l}\mathrm{NaOH} \text {, asam- } \\
\text { asam } \\
\text { mineral/organic, } \\
\text { garam-garam } \\
\text { natrium } \\
\end{array}$ & $\begin{array}{l}\text { Scouring, } \\
\text { desizeng, } \\
\text { bleaching, } \\
\text { merserizing, } \\
\text { dyeing }\end{array}$ \\
\hline Sulfur & $\begin{array}{l}\text { Sulfat, Sulfida, } \\
\text { garam-garm } \\
\text { Hydrosulfit dan } \\
\text { asam sulfur }\end{array}$ & Dyeing \\
\hline Zat-zat beracun & $\begin{array}{l}\text { Logam-logam } \\
\text { berat, zat } \\
\text { pereduksi, zat } \\
\text { pengoksidasi }\end{array}$ & $\begin{array}{l}\text { Desizing, } \\
\text { Bleaching, } \\
\text { Dyeing, } \\
\text { Finising }\end{array}$ \\
\hline $\begin{array}{l}\text { Bahan-bahan } \\
\text { organik tahan } \\
\text { api }\end{array}$ & $\begin{array}{l}\text { Surfaktan, zat } \\
\text { warna, resin, } \\
\text { kanji sintetik, } \\
\text { senyawaorganik } \\
\text { terklorinasi, } \\
\text { pelarut-pelarut } \\
\text { organik buatan }\end{array}$ & $\begin{array}{l}\text { Desizing, } \\
\text { Bleaching, } \\
\text { Dyeing, } \\
\text { Finising }\end{array}$ \\
\hline
\end{tabular}

Sumber :[6]

Proses adsorpsi juga dapat dikombinasi dengan metode membrane seperti proses nanofiltrasi. Material adsorsi seperti karbon aktif cukup mahal, oleh karena itu, perlu pemilihan material alami untuk proses adsorpsi.

Peningkatan adsorpsi dari silika dapat dilakukan dengan cara memodifikasi silika dari sekam padi. Proses modifikasi dapat dibentuk sebagai silika gel dan hibrida merkapto silika.

TABEL II

KOMPOSISI DAN KARAKTERISTIK LIMBAH INDUSTRI KECIL

\begin{tabular}{|c|c|c|c|c|}
\hline Parameter & $\begin{array}{c}\text { Zodi, } \\
\text { dkk. } \\
\mathbf{( 2 0 0 9 )}\end{array}$ & $\begin{array}{c}\text { Akanksha, } \\
\text { dkk. } \\
\mathbf{( 2 0 1 3}\end{array}$ & $\begin{array}{c}\text { Manenti, } \\
\text { dkk. (2014) }\end{array}$ & $\begin{array}{c}\text { Mukminin. } \\
\text { dkk. (2015) }\end{array}$ \\
\hline BOD (mg/L) & - & 2.674 & 200 & 44,54 \\
\hline COD (mg/L) & 3.260 & $\begin{array}{c}12.900- \\
17.800\end{array}$ & 1.200 & 470 \\
\hline $\mathrm{pH}$ & 7 & 4,68 & 11,3 & 11,7 \\
\hline $\begin{array}{c}\text { Konduktivi- } \\
\text { tas (mg/cm) }\end{array}$ & 1,9 & - & 18 & - \\
\hline Nitrat (mg/L) & - & 5,28 & 3,3 & - \\
\hline $\begin{array}{c}\text { Klorida } \\
(\mathrm{mg} / \mathrm{L})\end{array}$ & - & 199,93 & 5.500 & - \\
\hline Sulfat (mg/L) & - & 8,98 & 119 & 0,757 \\
\hline Fosfat (mg/L) & - & 39,40 & $<0,2$ & - \\
\hline Krom & - & - & - & $<0,03$ \\
\hline
\end{tabular}

Sumber : [8]

\subsection{Silika Abu Sekam Padi}

Silika adalah senyawa hasil polimerisasi asam silikat, yang tersusun dari rantai satuan $\mathrm{SiO}_{4}$ tetrahedral dengan formula umum $\mathrm{SiO}_{2}$ [9]. Silika merupakan komposisi paling besar dari sekam padi, yaitu sekitar $90 \%$ dari total komposisi penyusun sekam padi lainnya, dapat dilihat pada Tabel 3.

Proses ekstraksi silika dapat dilakukan dengan cara pembakaran pada suhu tinggi kemudian proses alkalinasi. Pada percobaan [4] proses ekstraksi silika dari sekam padi dilakukan dengan cara membakar sekam dalam tunguku perapian pada suhu 700 oC selama 4 jam, kemudian dilakukan ekstraksi menggunakan alkali (digunakan larutan $\mathrm{NaOH} 1 \mathrm{~N}$ ) pada suhu $80{ }^{\circ} \mathrm{C}$ selama 1 jam.

Proses ekstraksi silika dari sekam padi melalui pencucian awal dengan asam memberikan kemurnian yang cukup tinggi setelah dilakukan pembakaran pada suhu $600 \mathrm{oC}[5]$ dan pada suhu $750{ }^{\circ} \mathrm{C}[10]$.

Karakterisasi silika sekam padi melalui uji Scanning Electron Microscope (SEM), Fourier Transform Infra Red (FTIR), X-Ray Diffraction (XRD), dan Brunaeur - Emmet - Teller (BET) adalah sebagai berikut [5][10] :

1. Silika mengadung gugus silanol (gugus $\mathrm{OH})$ sehingga lebih hydrous

2. Struktur dan karakteristik pori silika sekam padi tidak mengalami perubahan (tetap 
bersifat amorf) hingga pembakaran sampai suhu $600{ }^{\circ} \mathrm{C}-750{ }^{\circ} \mathrm{C}$.

3. Memiliki luas permukaan spesifik yang cukup tinggi, sehingga dapat dimanfaatkan sebagai adsorben.

Kenaikan suhu sintering mulai $1000{ }^{\circ} \mathrm{C}$ mulai mempengaruhi gugus fungsional silika dari sekam padi secara signifikan, hal ini memperlihatkan bahwa terjadi kristalisasi yang mengakibatkan jerjadinya pemadatan pada struktur silika sekam padi [11]. Analisis SEM sampel cordierite hasil sintesis dari silika sekam padi yang mengalami sintering dan tidak mengalami sintering dapat dilihat pada Lampiran.

TABEL III

KOMPOSISI SEKAM PADI

\begin{tabular}{|c|c|c|}
\hline \multirow{2}{*}{ Komposisi } & \multicolumn{2}{|c|}{ Presentase } \\
\cline { 2 - 3 } & $\begin{array}{c}\text { Bose, dkk. } \\
(2016)\end{array}$ & $\begin{array}{c}\text { Bakar, dkk. } \\
(2016)\end{array}$ \\
\hline $\mathrm{SiO}_{2}$ & $86,9-96,3$ & 99,083 \\
\hline $\mathrm{K}_{2} \mathrm{O}$ & $0,58-2,5$ & 0,016 \\
\hline $\mathrm{Na}_{2} \mathrm{O}$ & $0-1,75$ & - \\
\hline $\mathrm{MgO}_{2}$ & $0,12-1,96$ & 0,035 \\
\hline $\mathrm{P}_{2} \mathrm{O}_{5}$ & $0,2-2,85$ & 0,130 \\
\hline $\mathrm{CaO}^{*}$ & $0,2-1,5$ & 0,050 \\
\hline $\mathrm{SO}_{3}$ & $0,1-1,13$ & 0,046 \\
\hline $\mathrm{Cl}^{*}$ & $\mathrm{Tr}-0,42$ & - \\
\hline $\mathrm{Fe}$ & $\mathrm{Tr}-0,56$ & $\mathrm{Fe}_{2} \mathrm{O}_{3}=0,017$ \\
\hline $\mathrm{Al}_{2} \mathrm{O}_{3}$ & & 0,605 \\
\hline $\mathrm{Sumb}^{*}$ & & \\
\hline
\end{tabular}

Sumber : [3][5]

Tabel III meperlihatkan bahwa silika merupakan komposisi yang paling banyak dari komposisi penyusun sekam padi,yaitu berkisar sekitar $90 \%$.

\subsection{Mekanisme Pengolahan Limbah Tekstil} dengan Silika Sekam Padi

Karakteristik silika sekam padi yang memiliki luas permukaan spesifik relatif tinggi dan memiliki struktur amorf, sehingga dapat dimanfaatkan sebagai adsorben.

Salah satu pengolahan limbah tekstil yaitu dengan proses adsorpsi. Proses adsorpsi menggunakan adsorben silika sekam padi, didukung dengan gugus silanol yang terdapat dalam silika sekam padi, adanya gugus ini meningkatkan polaritas, sehingga memungkinkan untuk mengikat senyawa-senyawa lainnya dalam larutan.

Kinetika laju adsorpsi limbah tekstil dengan silika dari sekam padi dapat dituliskan dalam persamaan berikut :

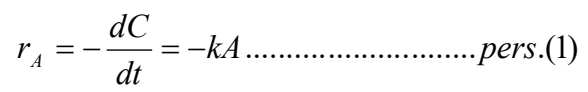

Pers. (1) diintegralkan didapat :

$$
\ln \left(\frac{C_{A}}{C_{A 0}}\right)=-k t
$$

Dimana:

$\mathrm{C}_{\mathrm{A}}=$ konsentrasi akhir limbah tekstil

$\mathrm{C}_{\mathrm{A} 0}=$ konsentrasi awal limbah tekstil

$\mathrm{t}$ = waktu akhir - waktu awal dan konversi limbah tekstil dalam

$\mathrm{X}=\left(\mathrm{C}_{\mathrm{A} 0}-\mathrm{C}_{\mathrm{A}}\right) / \mathrm{C}_{\mathrm{A} 0}$

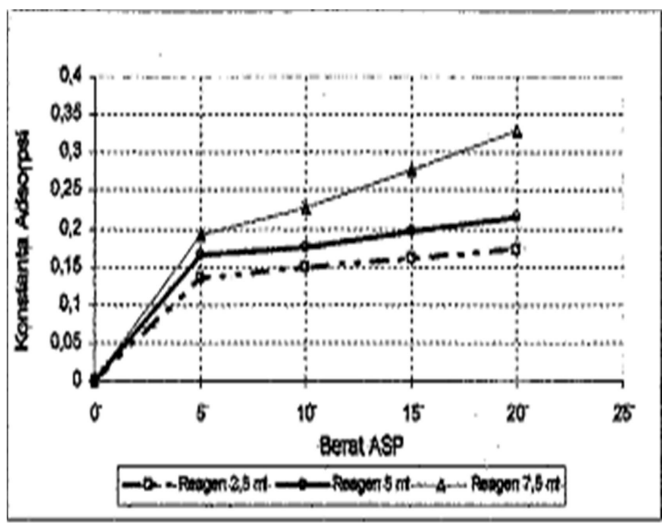

Gambar 1. Hubungan Berat Abu Sekam Padi dengan Konstanta adsorpsi

Sumber : [12]

Gambar 1 menunjukan bahwa dengan bertambahnya Abu sekam padi yang tambahkan sebagai adsorben maka akan menaikan konstanta adsorpsi, berarti akan semakin banyak jumlah limbah yang teradsorpsi.

Proses pengolahan limbah dengan memanfaatkan silika dapat dilakukan dengan metode membrane silika, campuran silika pada membrane PVC akan meningkatkan filtrasi dari limbah cair tekstil, terindikasi dengan menurunnya kekeruhan pada limbah yang ditandai dengan meningkatnya koefisiean rejeksi. Meningkatnya koefisien rejeksi maka meningkat pula kemampuan membrane untuk mefiltrasi limbah [13], dapat dilihat pada gambar 2. 


\section{JMTS|}

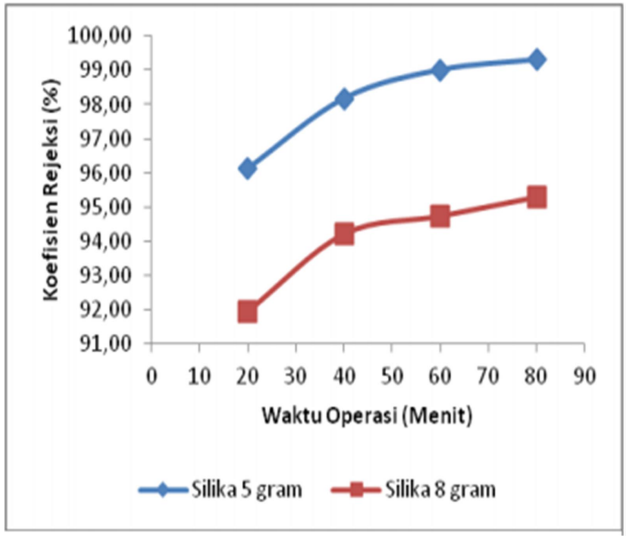

Gambar 2. Nilai Koefisien Rejeksi Kekeruhan pada Variasi Volume Limbah 100\%

Sumber : [13]

Pengembangan pemanfaat silika sebagai adsorben yaitu dengan mengkombinasi dengan kitosan. Kombinasi ini dikenal dengan membran komposit kitosan dan silika abu sekam padi. Membrane jenis ini akan meningkat adsorpsi terhadap logam seperti $\mathrm{Cr}(\mathrm{VI})$ [14] $\mathrm{Pb}^{2+}$ dan $\mathrm{Cu}^{2+}[15]$.

\section{KESIMPULAN}

Limbah-limbah tektil dihasilkan dari semua proses dalam industry tekstil mulai dari proses pretreatment sampai dengan finishing.

Silika yang berasal dari abu sekam padi dapat dimanfaatkan sebagai adsorben limbah tekstil, baik adsorpsi mengggunakan reagen atupun menggunakan membran.

Struktur amorf dan luas permukaan spesifik yang relatif tinggi dari silika dapat dipertahankan dengan suhu ekstrksi silika berada di rentang 500 ${ }^{\circ} \mathrm{C}-900{ }^{\circ} \mathrm{C}$.

Perlu dilakukan pengujian lebih detail untuk mendapatkan konsetrasi optimal dari silika sekam padi yang harus ditambahkan dalam proses adsorpsi menggunakan reagen ataupun filtrasi menggunakan membran.

\section{REFERENSI}

[1] Reni Amaranti, Drajad Irianto, and Rajesri Govindaraju, "Green Manufacturing : Kajian Literatur," in Seminar dan Konferensi Nasional IDEC 2017, Surakarta, 2017, pp. 171-181.

[2] Nurhasni, Hendrawati, and Nubzah Saniyyah, "Sekam Padi untuk Menyerap Ion Logam
Tembaga dan Timbal dalam Air," Valensi, p. 131, 2014.

[3] Dwarka Nath Bose, "Innovative process for preparation of multi- crystalline Silicon from rice-husk," in International Conference on Emerging Technologies and Innovative Business Practices for the Transformation of, 2016.

[4] Prima Astuti Handayani, Eko Nurjanah, and Wara Dyah Pita Rengga, "Pemanfaatan Limbah Sekam Padi Menjadi Silika Gel," Jurnal Bahan Alam Terbarukan, vol. 4, no. 2, 2015.

[5] Rohani Abu Bakar, Rosiyah Yahya, and Seng Neon Gan, "Production of High Purity Amorphous Silica from Rice Husk," in 5th International Conference on Recent Advances in Materials, Minerals and Environment, 2016, pp. 189-195.

[6] Himanshu Patel and R.T. Vashi, Characterization and Treatment of Textile Wastewater.: Elsevier, 2015.

[7] Serkan Arslan, Murat Eyvaz, Ercan Gürbulak, and Ebubekir Yüksel, "A Review of State-ofthe-Art Technologies in Dye-Containing Wastewater Treatment - The Textile Industry Case," in Textile Water Treatment.: ExLi4EvA, 2016.

[8] Jumardin Rua, Mega Maghfirotul Fajrin Yulan, Zaina Rohayati, and Riyanto, "Application of Electro-Oxidation Method for Treatment of Dye Textile Wastewater Using Stainless Steel Electrode: Study of Electrolyte Concentration Effect to Color Removal ," Eksakta : Jurnal Ilmu-Ilmu MIPA, vol. 17, no. 2, pp. $147-153,2017$.

[9] Siti Sulastri and susila Kristianingrum, "Berbagai Macam Senyawa Silika : Sintesis, Karakterisasi dan Pemanfaatannya," , Yogyakarta, 2010, pp. K-211 - K-266.

[10] Andy Chandra, Y.I.P. Arry Miryanti, Livia Budyanto Widjaja, and Andika Pramudita, "Isolasi dan Karakterisasi Silika dari SekamPadi," 2012.

[11] Simon Sembiring, Posman Manurung, and Pulung Karo-Karo, "Pengaruh Suhu Tinggi terhadap Karakteristik Keramik Cordierite Berbasis Silika Sekam Padi," Jurnal Fisika dan Aplikasinya, vol. 5, no. 1, pp. 090107-1 090107-4, 2009.

[12] Okik Hendriyanto Cahyo Nugroho, "Kinetika Adsorpsi Warna Limbah Tekstil dengan Abu Sekam Padi Menggunakan Reagen Tawas," Jurnal Teknik Kimia, vol. 1, no. 2, April 2007. 
[13] Veny Rachmawati and Alia Damayanti, "Pengolahan Limbah Cair Industri Pewarnaan Jeans Menggunakan Membran Silika Nanofiltrasi Aliran Cross Flow untuk Menurunkan Warna dan Kekeruhan," JURNAL TEKNIK POMITS, vol. 2, no. 2, pp. D-113 - D-118, 2013.

[14] Fifia Zulti, Kiagus Dahlan, and Purwantiningsih Sugita, "Adsorption of Waste Metal Cr(VI) with Composite Membranes (Chitosan-Silica Rice Husks)," Makara Journal of Science, pp. 163 - 168, 2012.

\section{Lampiran}

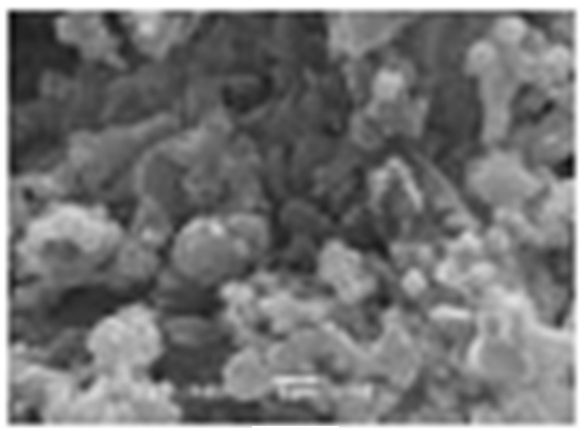

(a)

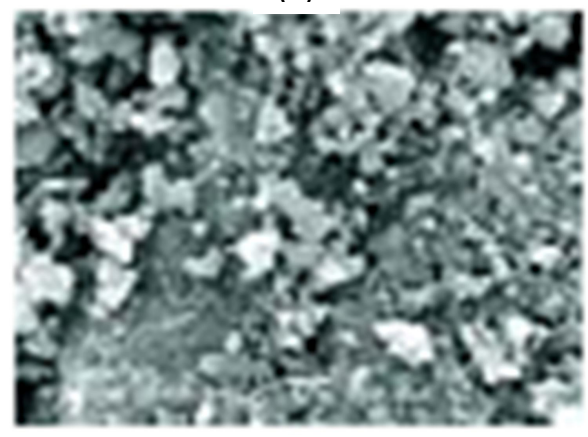

(b)
[15] Ani Mulyasuryani, Barlah Rumhayati, Chandrawati Cahyani, and Soebiantoro, "Adsorpsi $\mathrm{Pb}^{2+}$ dan $\mathrm{Cu}^{2+}$ Menggunakan Kitosan-Silika dari Abu Sekam Padi," Valensi, vol. 3, no. 2, pp. 88 - $92,2013$.

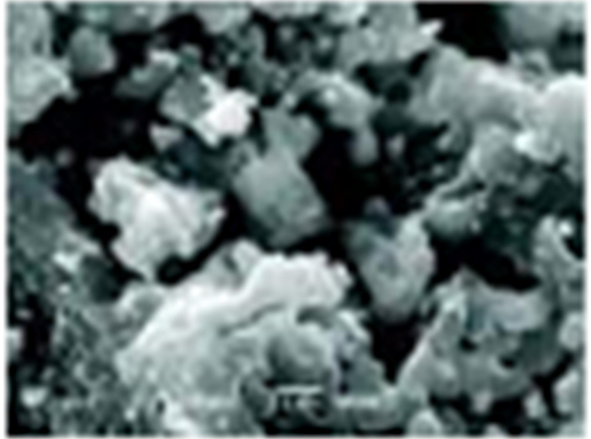

(c)

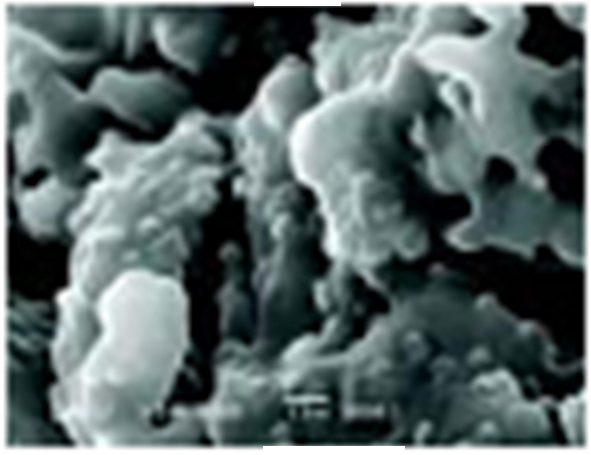

(d)

Analisis SEM sampel cordierite hasil sintesis dari silika sekam padi (a) tanpa sintering, (b) $1000{ }^{\circ} \mathrm{C},(\mathrm{c}) 1200{ }^{\circ} \mathrm{C}$ dan (d) $1400 \circ \mathrm{C}$

Sumber : [11] 